\title{
ChemComm
}

\section{A highly cytotoxic modified paullone ligand bearing a TEMPO free-radical unit and its copper(II) complex as potential hR2 RNR inhibitors $†$}

\author{
Cite this: Chem. Commun., 2013, \\ 49, 10007 \\ Received 27th July 2013, \\ Accepted 3rd September 2013
}

DOI: $10.1039 /$ c3cc45743e

\author{
Anatolie Dobrov, ${ }^{a}$ Simone Göschl, ${ }^{a}$ Michael A. Jakupec, ${ }^{a}$ Ana Popović-Bijelić, ${ }^{b}$ \\ Astrid Gräslund, ${ }^{C}$ Peter Rapta ${ }^{d}$ and Vladimir B. Arion*a
}

www.rsc.org/chemcomm

A new paullone-TEMPO conjugate and its copper(II) complex inhibit RNR activity and show high antiproliferative activity in human cancer cell lines.

Platinum-based drugs are widely used in the clinic against cancer. They exert their effect mainly by DNA binding leading finally to apoptosis. This mode of action is highly unselective, and the clinical application of these drugs is accompanied by severe side effects. ${ }^{1}$ Therefore, the development of metal-based drugs with targets other than DNA is an extremely important task. Over the last ten years we have reported metal complexes, organoruthenium(II) and organoosmium(II) compounds with a series of modified paullone ligands as potential Cdk inhibitors and showed that they possess high antiproliferative activity in vitro. ${ }^{2}$ However, a correlation between the Cdk inhibitory activity and cytotoxicity has not been established. Quite recently we have prepared highly antiproliferative ruthenium(II)- and osmium(II)-arene-based paullones bearing a TEMPO free-radical unit. ${ }^{3}$ The antitumour activity of nitroxyl radicals is well-documented in the literature. ${ }^{4}$ They show cytotoxicity in tumour cell lines ${ }^{5,6}$ and activity in animal tumour models. ${ }^{6,7}$ Investigations of conjugates, in which nitroxyl radical-containing units are covalently bound to antitumour compounds have attracted growing attention of researchers. ${ }^{8}$ Nitroxyl radicals possess unique antioxidant properties due to their ability to interact with free radicals. ${ }^{4}$ On the other hand, 4-hydroxy-2,2,6,6tetramethyl-piperidine-1-oxyl (Tempol) has been reported to promote oxidative stress in leukemia cells. ${ }^{5}$ This prompted us to investigate the anti-/pro-oxidative properties of paullone-TEMPO conjugates,

\footnotetext{
${ }^{a}$ Institute of Inorganic Chemistry of the University of Vienna, Währinger Strasse 42, A-1090 Vienna, Austria. E-mail: vladimir.arion@univie.ac.at

${ }^{b}$ Faculty of Physical Chemistry, University of Belgrade, 11158 Belgrade, Serbia

${ }^{c}$ Department of Biochemistry and Biophysics, Stockholm University,

S-10691 Stockholm, Sweden

${ }^{d}$ Department of Physical Chemistry, Slovak University of Technology,

Radlinského 9, SK-81237 Bratislava, Slovak Republic

$\dagger$ Electronic supplementary information (ESI) available: Materials and methods, synthetic procedures, EPR spectra, details of crystal structure of $\left[\mathrm{Cu}\left(\mathrm{L}^{2}\right) \mathrm{Cl}\right]$, concentration effect curves of the tested compounds in six human cancer cell lines, quantification of apoptosis induction in SK-Mel-28 and SW480 cells. CCDC 952588. For ESI and crystallographic data in CIF or other electronic format see DOI: $10.1039 / \mathrm{c} 3 \mathrm{cc} 45743 \mathrm{e}$
}

in particular their interaction with the tyrosyl radical $\left[\mathrm{Y}^{\bullet}\right]$ in the $\mathrm{R} 2$ subunit of human ribonucleotide reductase enzyme (hR2 RNR) as well as their influence on cellular levels of reactive oxygen species (ROS). We show that a new type of modified paullones bearing a tridentate binding site and a free-radical TEMPO unit and its copper(II) complex are highly cytotoxic and are able to destroy the $\left[\mathrm{Y}^{\bullet}\right]$ in hR2 RNR. The RNR enzyme catalyzes the reduction of four ribonucleotides to their corresponding deoxyribonucleotides, providing precursors required for both synthesis and repair of DNA. ${ }^{9}$

The synthesis of $\mathbf{H L}^{\mathbf{1}}$ and $\mathbf{H L}^{\mathbf{2}}$ was performed in three steps, starting from 9-carboxy-7,12-dihydroindolo[3,2- $d][1]$ benzazepin-6(5H)one, as shown in Scheme S1, ESI. $†$ First the lactam group was thionated as reported previously, ${ }^{3}$ and then thiolactam $\mathbf{A}$ was allowed to react with 2-acetylpyridine hydrazone with formation of species $\mathbf{B}$, containing a tridentate binding site to accommodate metal ions. 2,2,6,6-Tetramethylpiperidine or TEMPO radical units were attached onto the paullone backbone through a carboxylic group by formation of an amide bond in a DMF solution in the presence of triethylamine, 1-hydroxybenzotriazole and 1-ethyl-3-(3-dimethylaminopropyl)carbodiimide hydrochloride (EDCI). Final purification of ligands $\mathbf{H L}^{1}$ and $\mathbf{H L}^{2}$ was performed by HPLC.

Using the reaction of $\mathbf{H L}^{\mathbf{1}}$ and $\mathbf{H L}^{2}$ with $\mathrm{CuCl}_{2}$ in methanol or water-THF, copper(II) complexes $\left[\mathrm{Cu}\left(\mathbf{H L}^{\mathbf{1}}\right) \mathrm{Cl}_{2}\right] \cdot 3 \mathrm{H}_{2} \mathrm{O} \cdot 0.5 \mathrm{MeOH}(\mathbf{1})$ and $\left[\mathrm{Cu}\left(\mathrm{HL}^{2}\right) \mathrm{Cl}_{2}\right] \cdot 1.8 \mathrm{H}_{2} \mathrm{O}(2)$ were prepared in 85 and $87 \%$ yields, respectively (Fig. 1). Both the ligands and complexes (1 and 2) were characterized using elemental analysis, IR, EPR spectroscopy and ESI mass spectrometry. The presence of five-coordinate copper(II) in 1 and 2 was assumed from previous X-ray diffraction analysis of related complexes with a bromo substituent in position 9 of the paullone backbone. $^{2 d}$ Re-crystallization of 2 from THF is accompanied by deprotonation of the ligand and isolation of the complex $\left[\mathrm{Cu}\left(\mathrm{L}^{2}\right) \mathrm{Cl}\right]$. $0.5 \mathrm{THF}$, which has been studied by X-ray crystallography (vide infra). $\neq$ The formation of ligands and complexes $\mathbf{1}$ and $\mathbf{2}$ is corroborated by ESI mass spectrometry. The peaks with $\mathrm{m} / \mathrm{z} 645$ and 660 were attributed to $[\mathrm{M}-\mathrm{Cl}]^{+}$ions, while those with $\mathrm{m} / \mathrm{z} 609$ and 624 are due to $[\mathrm{M}-\mathrm{Cl}-\mathrm{HCl}]^{+}$ions. The presence of a TEMPO radical in $\mathbf{H L}^{2}$ and 2 was confirmed by EPR spectra of their $10^{-4} \mathrm{M}$ solutions in methanol or in 1:1 v/v MeOH-DMF. A typical triplet as reported previously ${ }^{3}$ with a tumbling effect pattern was observed (Fig. S1, ESI $\dagger$ ). 

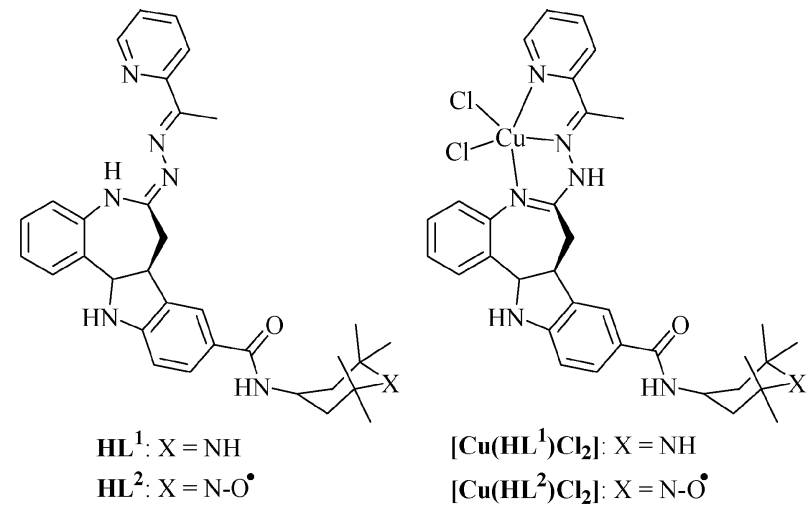

Fig. 1 Structures of ligands and their copper(॥) complexes.

Interaction between TEMPO radical $(S=1 / 2)$ and the paramagnetic copper(II) ion $(S=1 / 2)$ has not been observed. Note that the intramolecular separation between these two paramagnetic centres is about $14.25 \AA$.

The copper(II) ion in $\left[\mathrm{Cu}\left(\mathrm{L}^{2}\right) \mathrm{Cl}\right]$ has a square-pyramidal coordination environment $(\tau=0.04)^{10}$ with a tridentate monodeprotonated ligand $\left(\mathrm{L}^{2}\right)^{-}$bound to copper(II) via the azepine ring nitrogen atom $\mathrm{N} 1$, the hydrazine group nitrogen atom N20 and the pyridine nitrogen atom $\mathrm{N} 28$, as well as a chlorido ligand in the basal plane and an amide oxygen of a neighbouring metal complex in the apical position (Fig. 2 and Fig. S2, ESI $†$ ).

The sensitivity of the $\mathrm{R} 2$ specific $\left[\mathrm{Y}^{*}\right]$ in $\mathrm{hRNR}$ to $\mathbf{H L}^{2}$ and $\mathbf{2}$ was tested. A highly purified hR2 RNR protein ( $20 \mu \mathrm{M} \mathrm{R} 2$ monomer) in Tris buffer, $\mathrm{pH} 7.60 / 100 \mathrm{mM} \mathrm{KCl} / 5 \%$ glycerol was incubated with $20 \mu \mathrm{M}$ of the corresponding compound at $298 \mathrm{~K}$. The samples were analysed by EPR spectroscopy at $20 \mathrm{~K}$. The results obtained are shown in Fig. 3.

Both the ligand $\mathbf{H L}^{2}$ and copper(II) complex 2 show marked hR2 RNR inhibitory activity destroying more than $60 \%$ of $\left[\mathrm{Y}^{\bullet}\right]$ after 20 min incubation. Addition of $2 \mathrm{mM}$ dithiothreitol (DTT) to hR2 and 2 leads to complete tyrosyl radical destruction after $30 \mathrm{~s}$ incubation, while in the case of $\mathbf{H L}^{2}$ the remaining radical content after $30 \mathrm{~s}$ is $12 \%$.

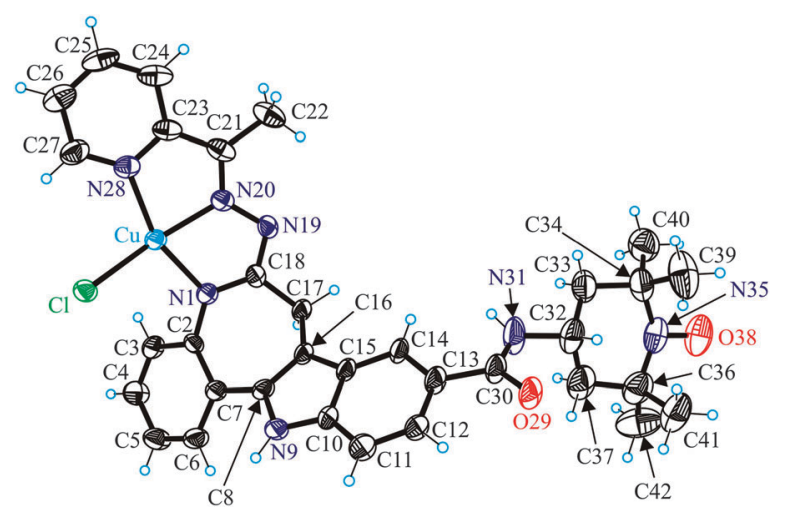

Fig. 2 ORTEP view of a molecule of $\left[\mathrm{Cu}\left(\mathrm{L}^{2}\right) \mathrm{Cl}\right]$ with atom labeling, showing thermal ellipsoids at $50 \%$ probability level. Selected bond distances $(\AA)$ and bond angles (deg): Cu-N1 1.978(5), Cu-N20 1.951(4), Cu-N28 2.028(5), Cu-Cl 2.2529(15), Cu-O29i 2.271(4), N35-O38 1.285(7), N1-Cu-N20 79.19(19), N20-CU-N28 79.64(19). Symmetry code $i: x, y, z+1$.

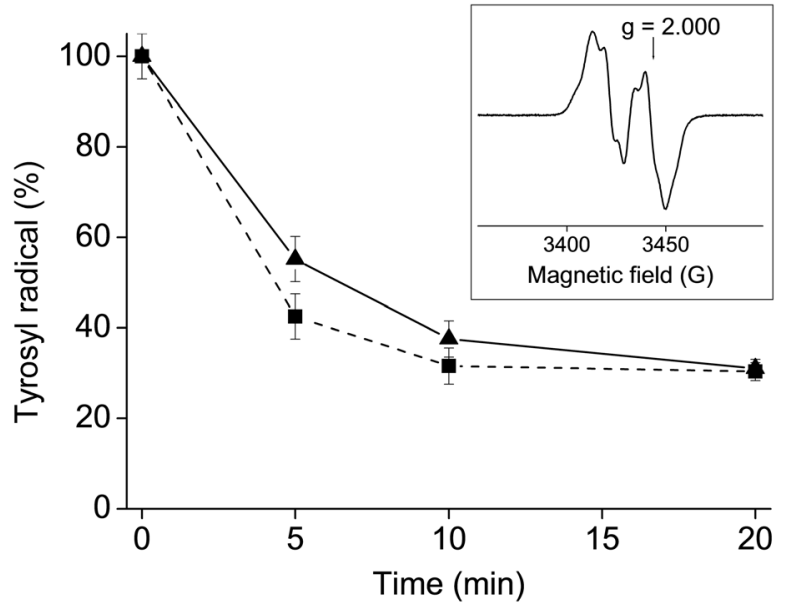

Fig. 3 Tyrosyl radical $\left[\mathrm{Y}^{\bullet}\right]$ destruction in human R2 RNR protein by $\mathbf{H L}^{2}$ (triangles) and 2 (squares). Samples containing $20 \mu \mathrm{M}$ human R2 protein and $20 \mu \mathrm{M}$ compound ( $1 \%(\mathrm{w} / \mathrm{w})$ DMSO- $\mathrm{H}_{2} \mathrm{O}$ ) in Tris buffer, $\mathrm{pH} 7.60 / 100 \mathrm{mM} \mathrm{KCl} / 5 \%$ glycerol, were incubated for indicated times and quickly frozen in cold isopentane. The natural decay of tyrosyl radical in the R2 protein was subtracted for each point. Inset: X-band EPR spectrum of the tyrosyl radical in human R2 RNR protein at $20 \mathrm{~K}$. Experimental conditions: frequency $9.63 \mathrm{GHz}$, microwave power $3.2 \mathrm{~mW}$, modulation amplitude $0.5 \mathrm{mT}$.

Table 1 Cytotoxicity of paullone ligands $\mathbf{H L}^{1}$ and $\mathbf{H L}^{2}$, and copper(॥) complexes 1 and $\mathbf{2}$ in six human tumour cell lines

\begin{tabular}{lcccc}
\hline & $\mathrm{IC}_{50},{ }^{a} 96 \mathrm{~h}$ & & \\
\cline { 2 - 5 } & $\mathbf{H L}^{\mathbf{1}}$ & $\mathbf{1}$ & HL $^{2}$ & 2 \\
\hline A549 & $0.22 \pm 0.02$ & $0.19 \pm 0.04$ & $0.063 \pm 0.009$ & $0.093 \pm 0.009$ \\
CH1 & $0.081 \pm 0.002$ & $0.056 \pm 0.003$ & $0.02 \pm 0.003$ & $0.037 \pm 0.007$ \\
SW480 & $0.17 \pm 0.03$ & $0.15 \pm 0.02$ & $0.27 \pm 0.05$ & $0.39 \pm 0.05$ \\
N87 & $0.22 \pm 0.04$ & $0.18 \pm 0.02$ & $0.027 \pm 0.009$ & $0.056 \pm 0.013$ \\
SK-Mel 28 & $0.70 \pm 0.03$ & $0.64 \pm 0.07$ & $0.031 \pm 0.005$ & $0.047 \pm 0.011$ \\
T47D & $0.13 \pm 0.01$ & $0.12 \pm 0.02$ & $0.13 \pm 0.03$ & $0.22 \pm 0.05$
\end{tabular}

${ }^{a} 50 \%$ inhibitory concentrations (means \pm standard deviations from at least three independent experiments), as obtained by the MTT assay using exposure times of $96 \mathrm{~h}$.

All compounds show high antiproliferative activity in vitro with $\mathrm{IC}_{50}$ values in the nanomolar range (Table 1 and Fig. S3, ESI $\dagger$ ). $\mathrm{CH} 1$ ovarian cancer cells are the most sensitive to all four compounds, whereas SW480 colon cancer cells or SK-Mel 28 melanoma cells are the least sensitive to compounds containing or lacking the radical unit, respectively. On average, the presence of a TEMPO radical instead of 2,2,6,6-tetramethylpiperidine results in increased cytotoxicity, but the actual effect depends very much on the cell line, varying from a maximum of 23 and 14 times increased potency of ligand and copper(II) complex, respectively, in SK-Mel-28 melanoma cells to an even slightly reverse effect in SW480 colon cancer cells. Complexation with copper(II) has little or no effect on the cytotoxicity in the presence or absence of the radical unit, respectively.

Generation of intracellular ROS by the compounds was determined by using the DCFH-DA assay in HL-60 leukemia cells. In general the compounds with a TEMPO radical moiety show a stronger induction of ROS than the compounds without the radical moiety (Fig. 4). Treatment with $20 \mu \mathrm{M}$ of 2 or $\mathbf{H L}^{2}$ results in a 2.7-fold or 3.5-fold enhancement of ROS levels, respectively, whereas $\mathbf{H L}^{\mathbf{1}}$ increases ROS levels by only two times and $\mathbf{1}$ shows negligible activity. 


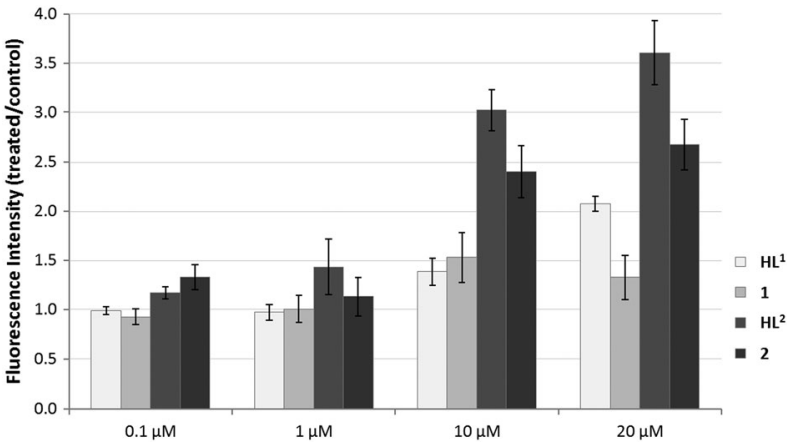

Fig. 4 Generation of intracellular ROS induced by treatment with compounds in the DCFH-DA assay. $\mathrm{H}_{2} \mathrm{O}_{2}(500 \mu \mathrm{M} ; 10$ min incubation) was used as a positive control.

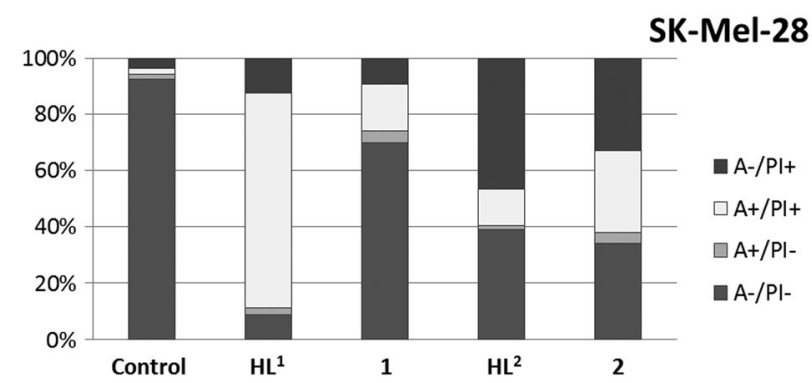

SW480

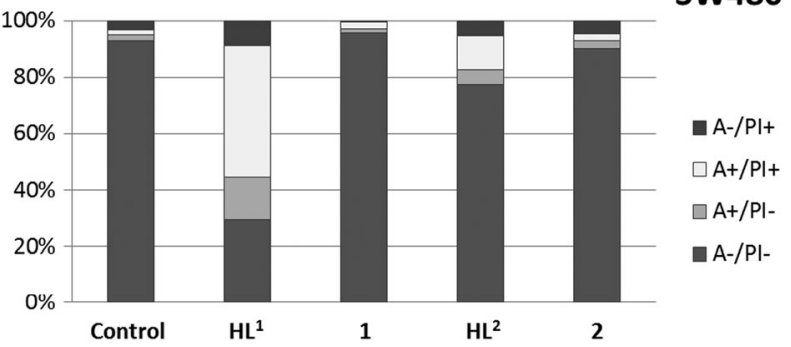

Fig. 5 Induction of apoptosis (annexin-positive and double positive cells) and necrosis (PI-only positive cells) after treatment with $20 \mu \mathrm{M}$ of compounds for $24 \mathrm{~h}$ in SW480 and SK-Mel-28 cells.

To determine apoptosis induction, SW480 and SK-Mel-28 cells were treated with different concentrations of the compounds for $24 \mathrm{~h}$. Afterwards, the cells were stained with Annexin V-FITC and propidium iodide, and 5000 cells were measured by flow cytometry. $\mathbf{H L}^{1}$ at $20 \mu \mathrm{M}$ concentration shows a remarkable induction of apoptosis of up to $61 \%$ in SW480 and 79\% in SK-Mel-28 cells. In contrast, the corresponding copper(II) complex shows no pronounced apoptosis induction in SW480, but up to $20 \%$ apoptosis in SK-Mel-28 cells. The ligand with a TEMPO-radical moiety $\left(\mathbf{H L}^{2}\right)$ induces less apoptosis in both cell lines, whereas enhanced necrosis was observed in SK-Mel-28 cells. The corresponding complex 2 induces apoptosis and necrosis in SK-Mel-28, but shows no activity in SW480 cells (Fig. 5 and Fig. S4, ESI $\dagger$ ). A comparison with results from the MTT assay suggests that especially the copper(II) complexes exert merely antiproliferative effects in SW480 cells, virtually without killing cells.

In conclusion, these compounds are extraordinarily cytotoxic in human cancer cell lines, with structural modifications (presence/absence of the radical moiety, complexation with copper(II)) exerting comparatively moderate effects on cytotoxic potency. On average, the presence of the TEMPO radical is advantageous but not in all cell lines. Whereas cell-free experiments suggest inhibition of ribonucleotide reductase activity by the anti-oxidative properties of the radical unit as a possible mechanism of action, enhanced generation of reactive oxygen species was observed in leukemia cells. Whether this is a direct or an indirect effect remains unclear. Similar divergent findings regarding anti-/pro-oxidative properties have been reported for 4-hydroxy-2,2,6,6-tetramethylpiperidine-1-oxyl (Tempol) by different authors (compare ref. 4 and 5). Nevertheless, the major contribution to biological activity has to be attributed to the modified paullone structure of the compounds at the original lactam unit with creation of potential tridentate binding site.

We thank Alexander Roller for collection of X-ray diffraction data. Financial support from Austrian Science Fund (FWF), project number P20897, is acknowledged.

\section{Notes and references}

† Crystal data for $\left[\mathrm{Cu}\left(\mathrm{L}^{2}\right) \mathrm{Cl}\right] \cdot 0.5 \mathrm{THF}: \mathrm{C}_{35} \mathrm{H}_{39} \mathrm{ClCuN}_{7} \mathrm{O}_{2.5}\left(M_{\mathrm{r}}=696.72 \mathrm{~g} \mathrm{~mol}^{-1}\right)$, monoclinic, $a=12.7891(7) \AA, \quad b=28.6933(15) \AA, c=11.9318(6) \AA ̊ ., \beta=$ $104.934(3)^{\circ}, V=4230.6(4) \AA^{3}, T=100(2) \mathrm{K}$, space group $P 2_{1} / c, Z=4$, 64065 coll. refl., 7391 indep. refl. $\left(R_{\text {int }}=0.1051\right), \mathrm{GoF}=1.031, R_{1}=$ $0.0829, \mathrm{w} R\left(F^{2}\right)=0.2386$.

1 (a) C. G. Hartinger, N. Metzler-Nolte and P. J. Dyson, Organometallics, 2012, 31, 5677; (b) A. Casini, C. G. Hartinger, A. A. Nazarov and P. J. Dyson, Top. Organomet. Chem., 2010, 32, 57; (c) B. Therrien, Top. Curr. Chem., 2012, 319, 35; (d) G. Sava, G. Jaouen, E. A. Hillard and A. Bergamo, Dalton Trans., 2012, 41, 8226; (e) G. Gianni, A. Bergamo and P. J. Dyson, Dalton Trans., 2011, 40, 9069; $(f)$ G. Gasser, I. Ott and N. Metzler-Nolte, J. Med. Chem., 2011, 54, 3; $(g)$ A. L. Noffke, A. Habtemariam, A. M. Pizarro and P. J. Sadler, Chem. Commun., 2012, 48, 5219; (h) P. C. A. Bruijnincx and P. J. Sadler, Curr. Opin. Chem. Biol., 2008, 12, 197.

2 (a) A. Dobrov, V. B. Arion, N. Kandler, W. Ginzinger, M. A. Jakupec, A. Rufinska, N. Graf von Keyserlingk, M. Galanski, C. Kowol and B. K. Keppler, Inorg. Chem., 2006, 45, 1945; (b) W. F. Schmid, R. O. John, G. Mühlgassner, P. Heffeter, M. A. Jakupec, M. Galanski, W. Berger, V. B. Arion and B. K. Keppler, J. Med. Chem., 2007, 50, 6343; (c) W. F. Schmid, S. Zorbas-Seifried, R. O. John, V. B. Arion, M. A. Jakupec, A. Roller, M. Galanski, I. Chiorescu, H. Zorbas and B. K. Keppler, Inorg. Chem., 2007, 46, 3645; (d) M. F. Primik, G. Mühlgassner, M. A. Jakupec, O. Zava, P. J. Dyson, V. B. Arion and B. K. Keppler, Inorg. Chem., 2010, 49, 302; (e) L. K. Filak, G. Mühlgassner, M. A. Jakupec, P. Heffeter, W. Berger, V. B. Arion and B. K. Keppler, JBIC, J. Biol. Inorg. Chem., 2010, 15, 903; $(f)$ G. Mühlgassner, C. Bartel, W. F. Schmid, M. A. Jakupec, V. B. Arion and B. K. Keppler, J. Inorg. Biochem., 2012, 116, 180.

3 V. B. Arion, A. Dobrov, S. Göschl, M. A. Jakupec, B. K. Keppler and P. Rapta, Chem. Commun., 2012, 48, 8559.

4 B. P. Soule, F. Hyodo, K. Matsumoto, N. L. Simone, J. A. Cook, M. C. Krishna and J. B. Mitchell, Free Radicals Biol. Med., 2007, 42, 1632.

5 M. B. Gariboldi, V. Rimoldi, R. Supino, E. Favini and E. Monti, Free Radicals Biol. Med., 2000, 29, 633.

6 S. Suy, J. B. Mitchell, A. Samuni, S. Mueller and U. Kasid, Cancer, 2005, 103, 1302.

7 N. P. Konovalova, G. N. Bogdanov, V. B. Miller, E. G. Rozantsev, M. B. Neiman and N. M. Emanuel, Dokl. Akad. Nauk SSSR, 1964, 157, 707.

8 V. D. Sen', A. A. Terent'ev and N. P. Konovalova, Russ. Chem. Bull., Int. Ed., 2011, 60, 7.

9 P. Reichard, Science, 1993, 260, 1773-1777.

10 A. W. Addison, T. N. Rao, J. Reedijk, J. Van Rijn and C. G. Verschoor, J. Chem. Soc., Dalton Trans., 1984, 1349. 